\title{
¿MÁS PODER AL PODER? \\ LAS FRACTURAS DEL CONSTITUCIONALISMO LATINOAMERICANO EN LA ACTUALIDAD Y SUS POSIBLES ALIVIOS DEMOCRÁTICOS \\ Hólger Paúl Córdova Vinueza
}

Universidad Central del Ecuador

Recibido: 08 - mayo - 2015, aprobado 07 - julio - 2015

\section{Resumen}

El presente trabajo propone la discusión de los derechos políticos o de participación como tema determinante para el presente y futuro de la democracia constitucional en nuestros países. Estos derechos, que significaron un sueño común para la formación del constitucionalismo latinoamericano en su etapa de independencia, por la búsqueda de soberanía y autodeterminación de nuestros pueblos, en la actualidad crean escenarios de tensiones para los sujetos sociales y políticos que no forman parte de los procesos institucionalizados del poder, entendiendo a estos como los gobiernos en funciones. Bajo esa correlación, el propósito es arrojar miradas integrales y globales que retraten las problemáticas y riesgos democráticos que enfrentan en su ejercicio. Para cumplir ese fin, este estudio contiene cinco secciones. La primera sección describe los argumentos político-jurídicos de los derechos en torno a la democracia constitucional; la segunda, establece los fundamentos de estos derechos humanos desde el derecho internacional; en un tercer momento, aborda un recorrido descriptivo y deductivo sobre las cartas constitucionales de varios países en materia de derechos a la participación; en una cuarta sección, señala las encrucijadas actuales de estos derechos como consecuencia y efecto de varios factores provenientes de nuestros sistemas constitucionales; para finalizar con las consideraciones más relevantes para los nuevos caminos, perspectivas y reformas que profundicen los derechos estudiados.

Palabras clave: constitucionalismo, democracia, latinoamérica, poder y soberanía popular.

\begin{abstract}
This paper proposes the discussion on participation rights or political rights as critical matter to the present and future of constitutional democracy in our countries. These rights, which meant a common dream for the formation of Latin American constitutionalism during its independence stage, due to the seeking of sovereignty and self-determination for our people, nowadays create stress scenarios for social and political subjects that are not part of the institutionalized processes of power, understanding these as incumbent governments. Under this correlation, the purpose is to shed comprehensive and global views that portray the democratic problems and risks that face in their exercise. To meet this end, this study contains seven sections. The first section describes the political and legal arguments of the rights, around constitutional democracy; The second section, establishes the foundations of these human rights from the international law's point of view; in the third one, approaches a descriptive and deductive path on the constitutional charters of several countries on matter of rights to participation; in the fourth section, notes the current crossroads of these rights as a result and effect of various factors that come from our constitutional systems; ending with the most relevant considerations for new ways, perspectives and reforms that deepen the rights studied.
\end{abstract}

Keywords: constitutionalism, democracy, latin america, power and popular sovereignty. 


\section{Democratización, participación y organización social como funda- mentos de los derechos políticos}

Los derechos políticos o de participación (en adelante, DP) han alcanzado un rol determinante para la democratización de los estados y el fortalecimiento de la democracia. Varias concepciones han formulado las perspectivas de ejercicio de estos derechos en esos ámbitos.

Un enfoque importante ha sido precisado a partir de los procesos de reforma del estado y la implementación de controles públicos no estatales ni privados que coadyuvan a la ampliación de los servicios sociales (Bresser Pereira y Cunill Grau, 1998, pp. 25-56). Otro ha estado orientado a vincular su aplicación con el desarrollo de organizaciones sociales y los cambios en la política por medio de una democracia participativa (De Sousa Santos y Avritzer, 2004, pp. 35-74). La implementación de políticas públicas acompañadas de mecanismos específicos de participación es otro de las nociones utilizadas para ubicar a los derechos políticos (Font, 2001, pp. 13-24). La ampliación e impulso de la sociedad civil conjuntamente con el ejercicio de libertades públicas y la activación de la política en la vida social se presentan como elementos relevantes para entender las dinámicas de los derechos políticos (Sauca Sano y Wences Simon, 2007, pp. 9-19). Y para completar este registro de los grandes lineamientos políticos y constitucionales que explican la trayectoria de los derechos de participación, es oportuno considerar su articulación con el conjunto de los derechos humanos, el combate a la pobreza y las políticas públicas para incidir en estos aspectos (Leiras, 2007, pp. 17-65).

Todas esas miradas reafirman la importancia de estos derechos para el constitucionalismo latinoamericano con la vigencia de sus sistemas democráticos, por cuanto expresan que su desarrollo también supone la evolución o tensiones que pueden existir para su indispensable complementariedad y armonización con la institucionalidad democrática.

\section{Los derechos políticos en el derecho internacional}

El Pacto Internacional de Derechos Civiles y Políticos ${ }^{14}$ adoptado por la Asamblea General de las Naciones Unidas el 16 de diciembre de 1966, se caracteriza por reconocer a la libre determinación de los pueblos y declara como derechos políticos, en el artículo 25, a la participación en la dirección de asuntos públicos, de forma directa o por sus representantes; elegir y ser elegido; y, a tener acceso en condiciones de igualdad a la función pública de cada país., posteriormente el Protocolo Facultativo del Pacto Internacional de Derechos Civiles y Políticos crea el mecanismo para que las personas puedan presentar denuncias contra estados miembros; la Convención Americana sobre Derechos Humanos o Pacto de San

14 Pacto Internacional de Derechos Civiles y Políticos [1966], adoptado y abierto a la firma, ratificación y adhesión por la Asamblea General en su Resolución 2200 A (XXI), de 16 de diciembre de 1966 y con entrada en rigor el 23 de marzo de 1976 de conformidad con el artículo 49, disponible en portal web institucional de la Agencia de la ONU para Refugiados, en la dirección $<$ http://www.acnur.org/ t3/fileadmin/scripts/doc.php?file=biblioteca/pdf/0015>. Consulta: 26 de diciembre de 2014. 
José de Costa Rica ${ }^{15}$ suscrita el 22 de noviembre de 1969 y que entraría en vigencia el 18 de julio de 1978 declara en el artículo 23 los siguientes derechos políticos:

1. Todos los ciudadanos deben gozar de los siguientes derechos y oportunidades:

a) de participar en la dirección de los asuntos públicos, directamente o por medio de representantes libremente elegidos;

b) de votar y ser elegidos en elecciones periódicas auténticas, realizadas por sufragio universal e igual y por voto secreto que garantice la libre expresión de la voluntad de los electores; y,

c) de tener acceso, en condiciones generales de igualdad, a las funciones públicas de su país.

2. La ley puede reglamentar el ejercicio de los derechos y oportunidades a que se refiere el inciso anterior, exclusivamente por razones de edad, nacionalidad, residencia, idioma, instrucción, capacidad civil o mental, o condena, por juez competente, en proceso penal.

Al utilizar la dimensión del derecho internacional de los derechos humanos y de conformidad al Acta Internacional de estos derechos, que incluye la Declaración Universal, los dos convenios de las Naciones Unidas y el Protocolo al Convenio sobre derechos civiles y políticos, Newman y Vasak explican a los derechos políticos como las facultades de la ciudadanía para participar en la conducción de los asuntos públicos, directamente o a través de representantes libremente elegidos, así como a elegir y ser elegido en elecciones periódicas veraces que deben celebrarse mediante sufragio universal e igual, y que deberá tener lugar por votación secreta, garantizando la libre expresión de la voluntad de los electores (Newman y Vasak, 1984, p. 200).

\section{Los derechos políticos o de participación en las Constituciones latinoamericanas}

\subsection{Constitución de la República del Ecuador}

Los DP descritos en el texto constitucional ${ }^{16}$ están ubicados en el capítulo quinto del título dos denominado Derechos, a partir del artículo 61, pero existen otros que han sido ubicados en el capítulo primero del título cuarto sobre Participación y Organización del Poder en otros artículos. En una visión integral son los siguientes:

1. Elegir y ser elegidos.

2. Participar en los asuntos de interés público.

15 Convención Americana sobre Derechos Humanos [1969] suscrita en la Conferencia Especializada Interamericana sobre Derechos Humanos (B-32) disponible en portal web de la Organización de los Estados Americanos en la dirección <http://www.oas.org/dil/esp/tratados B-32 Convencion Americana_sobre_Derechos_Humanos.htm>.Consulta: 26 de diciembre de $20 \overline{1} 4$.

16 Constitución de la República del Ecuador [2008], tít. II, “Derechos”, cap. V, arts. 61, 96, 98, Registro Oficial No. 449, de 20 de octubre de 2008. 
3. Presentar proyectos de iniciativa popular normativa.

4. Ser consultados.

5. Fiscalizar los actos del poder público.

6. Revocar el mandato que hayan conferido a las autoridades de elección popular.

7. Desempeñar empleos y funciones públicas con base en méritos y capacidades, y en un sistema de selección y designación transparente, incluyente, equitativo, pluralista y democrático, entre otros aspectos de igualdad y equidad.

8. Conformar partidos y movimientos políticos, afiliarse o desafiliarse libremente de ellos y participar en todas las decisiones que éstos adopten.

9. Ejercer la resistencia frente a acciones y u omisiones del poder público o de las personas naturales o jurídicas no estatales que vulneren o puedan afectar derechos.

10. Desarrollar formas y manifestaciones de organización de la sociedad para impulsar procesos de participación y decisión en la gestión de lo público o para intervenir en asuntos de interés colectivo.

Como novedades para tomar en cuenta, la Constitución ecuatoriana crea varias dimensiones institucionales para canalizar la participación social como las siguientes: a) Garantía para las políticas y servicios públicos. b) Principio para la gestión pública y la organización del poder. c) Función del estado. d) Derecho articulador del Sistema Nacional Descentralizado de Planificación Participativa. e) Elemento constitutiva del régimen de competencias. f) Deber y responsabilidad de la ciudadanía.

\subsection{Constitución Política del Perú}

A partir del capítulo III, artículo $30,{ }^{17}$ se agrupan los derechos políticos conjuntamente con algunos deberes ciudadanos. Los derechos del texto peruano tienen las siguientes características:

1. El derecho a la participación ciudadana contiene ámbitos institucionales para su ejercicio que son el referéndum; la iniciativa legislativa; la revocatoria de autoridades y la demanda de rendición de cuentas. Es importante destacar que el referéndum puede ser impulsado para aprobar lo siguientes procesos: a) Reforma total o parcial de la Constitución. b) Normas con rango de ley. c) Ordenanzas municipales. d). Materias sobre descentralización. ${ }^{18}$

17 Constitución Política del Perú [1993], tít. I, "De los Derechos Políticos y de los Deberes", cap. III, arts. desde 30 hasta 38, disponible en portal web institucional del Congreso de la República de Perú, en la dirección <http://www4.congreso.gob.pe/ntley/Imagenes/Constitu/Cons1993.pdf>. Consulta: 22 de diciembre de 2014. También consulté la versión publicada en el portal web institucional del Tribunal Constitucional de Perú, en la dirección <http://www.tc.gob.pe/constitucion.pdf $>$, actualizada hasta la modificación incorporada por la Ley No. 28480 publicada el 30-03-2005 en el Diario Oficial El Peruano. Consulta: 25 de diciembre de 2014.

18 No podrá someterse a referéndum la supresión o derechos constitucionales, ni las normas de carácter tributario o presupuestario, ni los instrumentos internacionales en vigor. 
2. El derecho de elegir y ser elegido, cuyo voto es personal, igual, libre, secreto y obligatorio hasta los setenta años. Este derecho también puede ser ejercido por los miembros de la fuerza pública.

3. El derecho y deber de participación vecinal o comunitaria en el respectivo gobierno municipal.

4. La participación en organizaciones políticas como partidos, movimientos o alianzas.

5. El asilo político y en caso de expulsión no se entrega el asilado al gobierno que lo persigue.

Como principios de protección importantes, es menester indicar que se establecen dos específicos: primero, que será nulo y punible todo acto que prohíba o limite al ciudadano el ejercicio de sus derechos; y, segundo, se obliga a que la ley defina mecanismos para garantizar la neutralidad estatal en los procesos electorales y de participación ciudadana, esta protección fue incorporada en la última reforma del año 2005. Otro elemento que merece ser destacado es que los miembros de la fuerza pública también pueden ejercer el derecho a la participación ciudadana, sin embargo, la misma norma constitucional prohíbe que incurran en actos de proselitismo, manifestaciones o postularse a cargos de elección popular, para lo cual deberán esperar a su retiro institucional.

Al finalizar este capítulo, la norma hace referencia a tres deberes ciudadanos como el honrar al país, proteger los intereses nacional y cumplir las normas constitucionales y jurídicas.

\subsection{Constitución de la nación Argentina}

El texto constitucional argentino ${ }^{19}$ incluye en el capítulo segundo un grupo denominado nuevos derechos y garantías, donde se reconocen los siguientes derechos políticos:

1. El derecho a la resistencia contra quienes ejecuten actos de fuerza contra el orden institucional y el sistema democrático.

2. Al sufragio en condiciones de universal, igual, secreto y obligatorio.

3. La igualdad real de oportunidades entre varones y mujeres para el acceso a cargos electivos y partidarios, para lo cual se garantizará acciones positivas en la regulación de partidos políticos y en el régimen electoral.

4. La iniciativa para presentar proyectos de ley en la Cámara de Diputados.

5. A ser consultados para la aprobación de un proyecto de ley ${ }^{20}$.

19 Constitución de la Nación Argentina [1994], primera parte, "Nuevos derechos y garantías", cap. II, arts. desde 36 hasta 40, disponible en portal web institucional del Senado de la Nación Argentina, en la dirección <http://www.senado.gov.ar/Constitucion/capitulo2>. Consulta: 22 de diciembre de 2014. También revisé la versión publicada por la Biblioteca del Congreso de la Nación, actualizada hasta la promulgación de la Ley 24.430, publicada en Boletín Oficial de la República Argentina el día 10 de enero de 1995 y disponible en el portal web institucional con la dirección $<\mathrm{http}$ //bibliotecadigital.csjn.gov.ar/Constitucion-de-la-Nacion-Argentina-Publicacion-del-Bicent.pdf $>$. Consulta: 25 de diciembre de 2014.

20 No serán objeto de iniciativa popular los proyectos que refieran a reforma constitucional, tratados internacionales, tributos, presupuesto y materia penal. 
6. A conformar organizaciones políticas, para lo cual se garantiza su funcionamiento, el acceso a la información pública y la difusión de sus ideas. El estado contribuye al sostenimiento económico de sus actividades y capacitación de sus dirigentes, con la obligación de la organización a dar publicidad del origen y destino de los fondos.

Las disposiciones constitucionales no poseen un desarrollo exhaustivo de los derechos políticos y sus mecanismos específicos como en otros textos normativos de otros países. A pesar que declara que la Constitución garantiza el pleno ejercicio de los derechos políticos, con arreglo al principio de la soberanía popular y de las leyes respectivas, tiene una disposición directa que reduce los amplios significados de la democracia participativa y la deliberación pública por cuanto establece lo siguiente en el artículo 22: "El pueblo no delibera ni gobierna, sino por medio de sus representantes y autoridades creadas por esta Constitución. Toda fuerza armada o reunión de personas que se atribuya los derechos del pueblo y peticione a nombre de éste, comete delito de sedición". Ese mandato constitucional podría entenderse como una primacía de la democracia representativa sobre las demás, que se reafirma con la disposición prevista en el último inciso del artículo 39, que determina los temas que no serán objeto de iniciativa popular donde consta los proyectos que traten de reforma constitucional.

\subsection{Constitución Política de Colombia}

El texto constitucional ${ }^{21}$ reúne todo el conjunto de derechos políticos en el art. 40 y presentan las siguientes características:

1. Elegir y ser elegido.

2. Participar en elecciones, plebiscitos, referendos, consultas populares y otras formas de intervención social.

3. Conformar organizaciones políticas sin limitaciones y difundir sus ideas y programas.

4. Revocar el mandato de las autoridades de elección popular.

5. Iniciativa en las corporaciones públicas.

6. Presentar acciones públicas en defensa de la Constitución y la ley.

7. Desempeñar cargos y funciones públicas.

Esos derechos incluyen como obligaciones para las autoridades que deberán garantizar la participación de la mujer en los espacios de decisión de la administración pública. De igual manera, se incluye la responsabilidad del estado para divulgar la Constitución, los principios y valores de la participación ciudadana.

21 Constitución Política de la República de Colombia [1991], tit. II, "De los Derechos, las Garantías y los Deberes", cap. I, arts. 40 y 41, disponible en el portal web de la Imprenta del Gobierno en $<\mathrm{http}: / /$ www.imprenta.gov.co/portal/page/portal/IMPRENTA/la_imprenta/Normatividad $>$ que contiene la última modificación por el Acto Legislativo 1 de 2008, publicada en el Diario Oficial No. 47.214 de 2008. Consulta: 22 de diciembre de 2014. 


\section{5. Constitución de la República Federativa de Brasil}

Los derechos políticos se fundamentan en la soberanía del pueblo y constan en el capítulo IV, ${ }^{22}$ desde el artículo 14 y presentan las siguientes características:

1. El derecho a elegir lo realizan mediante el voto directo y secreto con valor igual para todos, siendo obligatorio para los mayores de dieciocho años y facultativo para analfabetos, mayores de setenta años, mayores de dieciséis y menores de dieciocho años. ${ }^{23}$

2. Participar en plebiscito, referéndum e iniciativa popular.

3. Conformar e integrar organizaciones políticas, que tendrán acceso a recursos del fondo de partidos y acceso a medios de comunicación según condiciones establecidas por la ley.

Como un aspecto relevante, se instituye la obligación para que mediante ley se adopten las protecciones necesarias para la terminación de mandatos públicos con el fin de evitar la influencia del poder económico o el abuso del ejercicio de un función, cargo o empleo en la administración directa o indirecta, disposición constitucional que está ubicada en las normas relativas a los derechos políticos.

\section{6. Constitución de la República Bolivariana de Venezuela}

Los DP constan a partir del capítulo IV, artículo $62^{24}$ y están fundamentados en el principio de la participación del pueblo en la formación, ejecución y control de la gestión pública; $y$, son los siguientes:

1. Participar libremente en asuntos públicos, directamente o por medio de sus representantes elegidos.

2. A elegir y ser elegidos mediante el derecho de sufragio, ejercido en elecciones libres, universales y secretas. Pueden votar quienes poseen nacionalidad venezolana mayores de dieciocho años y los extranjeros con más de diez años de residencia.

3. A la rendición de cuentas de sus representantes de forma pública, transparente y periódica.

4. A asociarse con fines políticos mediante métodos democráticos de organización, funcionamiento y dirección.

22 Constitución de la República Federativa de Brasil [1988], tít. I, "Nuevos derechos y garantías”, cap. IV y V, arts. desde 14 hasta 17, traducción hecha por Antonio López Díaz y César García Novoa del texto vigente de 1988, promulgada el día 5 de octubre de 1988 y publicada en el Diario Oficial da Uniao No. 191-A del 5 de octubre de 1988. La versión consultada está publicada en Brasilia: Centro Gráfico del Senado Federal, 1990, disponible en portal web de la biblioteca jurídica de la Universidad Nacional Autónoma de México, en la dirección <http://biblio.juridicas.unam.mx/libros/4/1875/2.pdf>. Consulta: 22 de diciembre de 2014.

23 Para ejercer el derecho a ser elegido, la Constitución señala que no deben ser analfabetos y deben cumplir con un proceso de alistamiento electoral, para lo cual deben tener la nacionalidad brasileña, el pleno ejercicio de derechos políticos, el domicilio electoral en la circunscripción, la afiliación a un partido político y el cumplimiento de una edad mínima según la exigencia constitucional para las distintas postulaciones a autoridades de elección popular.

24 Constitución de la República Bolivariana de Venezuela [1999], tít. I, "Nuevos derechos y garantías", cap. IV y V, arts. desde 14 hasta 17, publicada en la Gaceta Oficial Extraordinaria No. 36.860 de 30 de diciembre de 1999, disponible en portal web de la Organización de Estados Americanos, en la dirección $<$ http://www.oas.org/dil/esp/Constitucion_Venezuela.pdf > . Consulta: 22 de diciembre de 2014. 
5. A manifestar públicamente, sin armas y con los requisitos que establezca la ley.

6. El asilo y refugio.

7. A ser consultados en temad de trascendencia nacional.

8. A revocar el mandato de cargos y magistraturas de elección popular.

9. A la iniciativa legislativa, constitucional y constituyente popular, y cuando se trate de proyecto de ley abrogatorio será sometido a referendo aprobatorio.

Cabe señalar que en la disposición constitucional del artículo 70, aparecen varios mecanismos específicos para canalizar la participación en ámbitos sociales y económicos como el cabildo abierto, la asamblea de ciudadanos y ciudadanas, instancias de atención ciudadana, cooperativas, cajas de ahorro, empresa comunitaria y otros instrumentos de gestión participativa. Finalmente, como otro aspecto para ponderar es que establece la obligación para que la ley establezca una representación proporcional del sistema electoral.

\section{7. Constitución del Estado Plurinacional de Bolivia}

Los derechos políticos se encuentran descritos en la sección $\mathrm{II}^{25}$, a partir del artículo 26 y fundamentado en el carácter soberano y democrático del estado, son los siguientes:

1. Participar en la formación, ejercicio y control del poder político, directamente o por medio de sus representantes, de forma individual y colectiva.

2. A la organización con fines de participación política.

3. Al sufragio que se ejercerá por voto igual, universal, directo, individual, secreto, libre y escrutado públicamente y lo podrán ejercer las personas desde los dieciocho años.

4. A desarrollar procesos comunitarios en los lugares donde se practique este tipo de democracia.

5. A elegir, designar y nominar directamente a los representantes de naciones y pueblos indígenas originarios y campesinos.

6. A fiscalizar actos de la función pública.

7. A pedir y recibir asilo o refugio por persecución política o ideológica a los extranjeros.

Como un primer elemento a destacar es que el artículo 26 de la Constitución determina el mandato de que la participación será equitativa y en igualdad de condiciones entre hombres y mujeres. Es relevante la norma que prevé la participación de las y los bolivianos que residen en el exterior para votar en procesos eleccionarios.

25 Constitución del Estado Plurinacional de Bolivia [2009], tít. II, sección II, "Derechos Políticos", cap. III, arts. desde 26 hasta 29, publicado el 7 de febrero de 2009, en la Gaceta Oficial del Estado Plurinacional de Bolivia, disponible en portal web de la Vicepresidencia Plurinacional de Bolivia en el sistema de información legal del Estado Plurinacional, en la dirección http://www.silep.gob.bo/ silep/constitucion. Consulta: 22 de diciembre de 2014. 


\section{8. Constitución Política de la República de Chile}

La Constitución chilena fue aprobada el 11 de septiembre de 1980, ha recibido 17 reformas y justamente la última del presente año incluye el voto de los ciudadanos chilenos en el exterior para la elección de Presidente y en plebiscitos. No contiene un grupo específico de derechos políticos, sino que están referidos con el resto de derechos fundamentales y está ubicado en el capítulo de nacionalidad y ciudadanía. Entre los artículos 13 y $15^{26}$, se describen como derechos de este tipo al sufragio, a ser consultados en plebiscito y a optar por cargos de elección popular; empero, también prevé otros derechos políticos que la ley pueda conferir. Con respecto a las votaciones, en el artículo 15 se define al sufragio como de personal, igualitario, secreto y voluntario. En cuanto al derecho al sufragio, son electores los ciudadanos chilenos mayores de 18 años, y para extranjeros lo podrán hacer quienes residan en el país por más de cinco años, que podrán votar en elecciones nacionales y municipales. Finalmente, en el artículo 18, consta el derecho a conformar e integrar organizaciones políticas, para lo cual señala la existencia de un sistema electoral público.

Como elementos relevantes, es oportuno indicar que el texto constitucional dispone que la ley creará los mecanismos para garantizar la plena igualdad entre la ciudadanía que participe en político mediante organizaciones partidarias o por postulaciones independientes, para ello definirá un sistema de financiamiento, transparencia, límite y control del gasto electoral.

\section{9. Constitución de la República Oriental de Uruguay}

La Constitución uruguaya de 1967 ha incorporado cuatro enmiendas plebiscitarias con la última de 2004, a pesar de ello es conocida como la de 1997. Ubica los derechos políticos en la sección III, capítulo ${ }^{27}$ y precisa el derecho a elegir y ser elegido, a ocupar empleos públicos, a la conformación e integración de organizaciones políticas y a ser consultado en referéndum. En materia de sufragio, el voto es secreto y obligatorio, deberá buscar la representación proporcional integral, se requiere la inscripción obligatoria en el Registro Cívico y para el caso de ciudadanos extranjeros se exige constitucionalmente la condición de tener buena conducta, profesar alguna ciencia, arte o industria y tener residencia habitual de 15 años.

26 Constitución Política de la República de Chile [actualizada hasta 2014], tít. II, sección II, "Nacionalidad y ciudadanía", cap. II, arts. desde 15 hasta 18, publicada con última reforma mediante Ley 20748 D.O. 03.05.2014 en el Diario Oficial de Chile, disponible en portal web de la Biblioteca del Congreso Nacional de Chile en la dirección <http://www.leychile.cl/Navegar?idNorma=242302>. Consulta: 23 de diciembre de 2014.

27 Constitución de la República Oriental de Uruguay [1997 con la última enmienda en 2004], sección III, "De la ciudadanía y del sufragio", cap. II, arts. desde 77 hasta 78. La versión utilizada tiene derechos reservados por su autor y por Industria Gráfica Nuevo Siglo Ltda./ Editorial Jurídica de Uruguay Eduardo Esteva/Ingranusi Ltda. El texto de la Constitución que entró en vigor en 1967 es reproducción del incluido en el Registro Nacional de Leyes y Decretos, 1967, t.I, ps. 119-203. El de la reforma constitucional parcial plebiscitada el 8-XII-1996 fue tomado del Diario Oficial No. 24.701, de 9-I-1997. Los de las enmiendas parciales plebiscitadas el 26-XI-1989 y el 27-XI-1994 reproducen los textos de los respectivos proyectos de reforma constitucional, no publicados en el Diario Oficial. En virtud de la técnica constituyente utilizada en 1996, los textos de los artículos, incisos, numerales y ordinales que se incluyen en negra son los verdaderamente adicionados o modificados por la reforma constitucional parcial plebiscitada el 8-XII-1996. De igual modo, se destacan los cambios incorporados por las reformas plebiscitadas en 1989 y 1994 . Esta versión está disponible en portal web de la Biblioteca de la Universidad Nacional Autónoma de México en la dirección < biblio.juridicas.unam.mx/libros/4/1739/15.pdf>. Consulta: 23 de diciembre de 2014 . 
Como aspectos a destacar, la Constitución dispone que los partidos políticos utilicen democracia interna para elegir a sus autoridades y que deberán realizar elecciones internas para elegir su candidato a la Presidencia. Por la importancia que tiene la ciudadanía en el texto constitucional para el ejercicio de estos derechos, llama la atención que en el artículo 80 se precise la suspensión de la ciudadanía por aspectos como la ineptitud física o mental, el ejercicio habitual de actividades moralmente deshonrosas, entre otras.

\section{10. Constitución Política de los Estados Unidos Mexicanos}

La Constitución de 1917 ha incorporado alrededor de 220 reformas, siendo la última en el presente año ${ }^{28}$. En una versión anterior se dividían los derechos políticos entre prerrogativas y deberes de los ciudadanos. En la actualidad, constan a partir del capítulo IV, desde el artículo 34 y son los siguientes:

1. A elegir y ser elegido.

2. A asociarse individual y libremente para tomar parte en forma pacífica en los asuntos políticos del país.

3. Tomar las armas en el Ejército o Guardia Nacional, para la defensa de la República y de sus instituciones, según la ley.

4. Ejercer en toda clase de negocios el derecho de petición.

5. Poder ser nombrado para cualquier empleo o comisión del servicio público.

6. Presentar proyectos de ley.

7. A ser consultado en temas de interés nacional ${ }^{29}$, por iniciativa del Presidente de la República, por una de las Cámaras del Congreso de la Unión, o por iniciativa ciudadana con el porcentaje de firmas de respaldo del $2 \%$ de los inscritos en la lista nominal de electores.

8. A conformar y participar en organizaciones políticas.

Como un aspecto trascendente, el texto mexicano dispone en el artículo 36 que los derechos de votar en las elecciones y en las consultas populares, desempeñar los cargos de elección popular de la Federación o de los Estados y desempeñar los cargos concejiles del Municipio donde resida, las funciones electorales y las de jurado son obligaciones del ciudadano de la República.

28 Constitución Política de los Estados Unidos Mexicanos [1917 actualizada hasta reforma de 2014], "De los ciudadanos mexicanos", cap. IV, art. 35, expedida con última reforma del 25 de junio de 2014 y publicada en la primera sección del Diario Oficial de la Federación el 7 de julio de 2014, disponible en portal web del H. Congreso de la Unión, Legislatura LXII, en la dirección $<$ http://www.diputados. gob.mx/LeyesBiblio/ref/cpeum_crono.htm>. Consulta: 23 de diciembre de 2014. También consulté la versión del texto publicada por la Secretaría de la Gobernación, actualizada hasta septiembre de 2014, vigésima primera edición al cuidado de la Dirección General Adjunta del Diario Oficial de la Federación, México, D.F., Talleres Gráficos de México, 2014, disponible en la dirección <http:// www.dof.gob.mx/constitucion/marzo_2014_constitucion.pdf>. Consulta: 25 de diciembre de 2014 .

29 Según el artículo 35, numeral 8, sección 3, No podrá ser objeto de consulta popular la restricción de los derechos constitucionales; los principios consagrados en el artículo 40 de esta; la materia electoral; los ingresos y gastos del Estado; la seguridad nacional y la organización, funcionamiento y disciplina de la Fuerza Armada permanente. La Suprema Corte de Justicia de la Nación resolverá previamente sobre la constitucionalidad de la materia de la consulta. 


\section{Limitaciones, problemáticas y riesgos democráticos}

En esta sección se precisan las contrariedades de los derechos políticos o de participación desde una mirada de los modelos constitucionales e institucionales de nuestros países. Si bien también existen esas que son propiciadas desde las dificultades del tejido social, el andamiaje de organizaciones partidarias, las deficiencias de los sistemas electorales, las contradicciones de la cultura e identidades políticas y las trayectorias de los movimientos ciudadanos; esta parte del estudio convocará aquellos tópicos basados en el primer ámbito formulado.

Para el ejercicio de los DP es indispensable que los textos constitucionales incorporen cláusulas de protección que garanticen las condiciones más libres, autónomas e independientes para su vigencia con respecto a la excesiva interferencia estatal. En el caso de la Constitución peruana, contiene principios de salvaguardia que procurarían velar por un ejercicio efectivo.

Los derechos políticos de participación necesitan una irrestricta materialización de los derechos civiles y libertades públicas para su plena realización. ${ }^{30}$ Las restricciones que encuentra la ciudadanía con relación a este último grupo influyen de manera determinante para su implementación. Derechos como la igualdad ante la ley se convierten en vitales para que las organizaciones sociales, políticas e individuos en general puedan activar e impulsar sus derechos ${ }^{31} \sin$ encontrar maniobras institucionales de parte de las gobiernos en funciones que pretenden favorecer a las organizaciones partidarias que representan en detrimento de las demás y sin garantizar la igualdad ante la ley del conjunto de la comunidad política.

Es indispensable contar con dispositivos institucionales específicos que incentiven los derechos políticos de las organizaciones partidarias que practican una política de oposición con relación al gobierno en funciones, por cuanto el rendimiento del andamiaje institucional puede ser utilizado en beneficio únicamente de organizaciones sociales y políticas que se presenten como aliadas con el gobierno oficialista.

La mayoría de los estados consultados tienen un sistema de gobierno presidencialista que se caracteriza por un esquema institucional de concentración y centralización del poder que genera serias dificultades para el desarrollo de una

30 Algunos autores vinculan el ejercicio de los derechos civiles y políticos. A continuación, cito un análisis en este sentido de John Brigham: "Los derechos tienen tantas posibilidades de ser la base para la crítica del statu quo como de su defensa. [...] Finalmente, la amenaza más siniestra a la democracia constitucional es la dominación de las libertades civiles por parte de los expertos, la profesionalización de la capacidad para tratar los derechos fundamentales. Las libertades civiles, como se presentaron aquí, forman parte del derecho constitucional, un derecho que es la expresión de la soberanía popular": Cfr. Las libertades civiles y la democracia estadounidense, (México: Gernika, 1987), 410-414.

31 Al respecto, Luis Aguilar de Luque sostiene lo siguiente: "Evidentemente cuando hablo de una más intensa y enérgica proyección del principio de igualdad sobre los derechos políticos me refiero a una igualdad en el tratamiento normativo, de modo que, por medio de ello, queda vedada toda discriminación en la ley reguladora de los derechos políticos y en la aplicación de la ley reguladora de tales derechos, siempre que dicha discriminación carezca de una justificación objetiva y razonable": Cfr. "Los derechos políticos" en Pablo Pérez Tremps, coord., Los derechos fundamentales, (Quito: Corporación Editora Nacional / Tribunal Constitucional / Universidad Carlos III e Iniciativa Europea para la Democracia y los Derechos Humanos de la Comisión Europea, 2004), 92. 
democracia participativa y deliberativa como condición sine qua non para los derechos políticos o de participación.

Los derechos políticos no son directamente empleados por las minorías políticas de los estados cuando sus derechos civiles han sido afectados, por esa razón hay una tendencia más recurrente para que los primeros puedan ser utilizados por las organizaciones que representan las mayorías políticas coyunturales gobernantes, mientras que las minorías puedan estar en una situación vulnerable para recurrir a sus DP.

Los modelos institucionales en cada país deben configurar mecanismos abiertos para participar con equilibrios y contrapesos públicos no estatales que promuevan mayores oportunidades de autonomía en la sociedad civil para activar los DP sin una subordinación institucional al estado, por cuanto las autoridades y funcionarios públicos son los encargados de aceptar y autorizar todos los instrumentos posibles de participación, lo cual entraña el riesgo de que las prácticas participativas sean avaladas y resueltas por las entidades estatales únicamente y se reduzcan así sus dinámicas societales independientes. El fenómeno de la estatización de la participación es precisamente una amenaza para los DP que no sólo se refiere a un diseño institucional donde predomina la intervención de las entidades estatales para crear y aprobar las instancias de participación, sino también cuando ciertos órganos del estado asumen atribuciones que pueden confundir su rol con respecto a los actores sociales, sino que pueden producir los efectos de desmovilizar o crear desencanto en las organizaciones de la sociedad para recurrir a los derechos de participación por no obtener resultados reales de su funcionamiento.

Cuando revisamos los casos de las Constituciones de Bolivia, Ecuador y Venezuela es posible identificar que se trata de los modelos que más podrían propiciar los DP, empero, sobresalen dos aspectos contradictorios y problemáticos: 1. Presentan regímenes presidenciales cuyo diseño no es proclive a la corresponsabilidad política para la definición de políticas públicas con las demás funciones del estado y la diversidad de organizaciones sociales y partidarias, sino que se inclinan por la primacía del poder ejecutivo. 2. Coinciden en que poseen instituciones muy relacionadas con la ejecución de actividades sobre participación y control social, sin embargo, no cuentan con suficientes mecanismos de representación social y de independencia de la función ejecutiva para suscitar las condiciones necesarias que garanticen el ejercicio plural, diverso, libre, igualitario, sin condicionamientos ni importunaciones para los movimientos y colectivos sociales.

La legislación penal de los estados estudiados conserva tipos penales propensos a criminalizar las protestas sociales y las manifestaciones públicas con fuertes implicaciones punitivas para la acción colectiva de disidencias y resistencias de los pueblos y movimientos societales.

Otro fenómeno es la tendencia de los estados para utilizar los DP como instrumentos para el disciplinamiento y el control social de las organizaciones y sujetos políticos. Aunque puede sonar a paradoja, el propósito es emplear el control social para el control social, lo cual supone que mediante los sistemas legales y la institucionalidad estatal se deben legitimar y legalizar los instrumentos de par- 
ticipación, y de esa manera, las capacidades soberanas y de autodeterminación de la sociedad quedan relegadas y desplazadas a la decisión de las instituciones para inspeccionar, vigilar y someter al ciudadano.

Aunque constituciones como la ecuatoriana y argentina declaran el derecho a la resistencia, y otras reconocen el derecho de asociación y reunión como derecho político en unos casos, y otros como derecho civil, en la práctica es un derecho que se presenta como inviable.

Es probable que los sistemas constitucionales deban insertar garantías específicas para los derechos políticos que tengan un tratamiento especial y distinto, y a lo mejor una discusión pertinente para los estados es si convendría fortalecer las garantías institucionales y jurisdiccionales con la finalidad de que los tipos de derechos puedan ser atendidos en su afectación con garantías diferentes porque la naturaleza, ámbito, fundamentos, pertinencia y oportunidad responden a situaciones de vulneración muy particulares.

Los DP necesitan de normas infraconstitucionales que pueden potenciar sus ámbitos de acción con cauces institucionales de articulación, cooperación y coordinación para las políticas públicas. A veces, las normas orgánicas tienden a crear institucionalidad con criterios de superposición de unas frente a otras y con escasos niveles de desarrollos concurrentes de competencias, lo cual significa una dificultad para los derechos políticos en tanto no todas las entidades públicas cuentan con suficientes políticas y prácticas participativas que puedan convertirse en receptoras y amplificadoras de las dinámicas sociales.

Los textos constitucionales analizados, con excepción de Ecuador y Venezuela, no contienen principios ni disposiciones para reconocer las grandes oportunidades para la gestión local y comunitaria que suponen los DP. Incluso, sería pertinente que puedan incorporar como disposición constitucional de promoción, o a manera de política pública, que los niveles subnacionales de gobierno puedan crear figuras propias de participación social en los niveles locales. Bajo esta perspectiva, algunos textos constitucionales sí podrían definir como criterios de políticas o de directrices constitucionales que los DP se vinculen con planes de ordenamiento territorial para crear dinámicas participativas que funcionen mediante agregaciones territoriales y con organizaciones sociales temáticas que pueden intervenir en la implementación de políticas sectoriales.

Cabe señalar en este sentido, que las políticas públicas del continente deben pensar en mecanismos que vinculen el ejercicio de DP con derechos civiles como el de asociación para promover la organización social, y que inclusive puedan ser los sujetos sociales los que puedan tener suficientes mecanismos de deliberación pública con las entidades estatales para participar en los procesos de definición de agendas y prioridades de políticas. Este tipo de innovaciones requerirían de reformas institucionales orientadas a asegurar ciertas pautas de seguimiento para el cumplimiento de estas complementariedades.

Un problema serio que se presenta en las normas supremas de los estados es la preponderancia de la democracia representativa sobre la participativa y la construcción de un modelo de autoridad que no reconoce formas de cogobier- 
no con la sociedad, sino en el mejor de los casos: la posibilidad de participar en ciertos programas sociales, pero no asegura formas institucionales de gobierno ni toma de decisiones en niveles de corresponsabilidad y cogobierno con los sujetos sociales. Este correlato es una herencia de la democracia liberal reductora de la participación y uno de los rezagos coloniales que no fue capaz de promover otras dimensiones más amplias y horizontales con la comunidad para construir la autoridad y los liderazgos públicos.

Otra limitación constitucional es la precariedad de disposiciones que aseguren que la toma de decisiones en las políticas públicas se construyan con procesos participativos y cómo estos pueden convertirse en vinculantes para aquellas. Incluso, mecanismos previstos como la Consulta Previa en instrumentos internacionales deberían ser parte de los textos constitucionales del continente para asegurar su condición vinculante y obligatoria para las políticas.

Las constituciones latinoamericanas deben actualizar su visión de la democracia y del estado en la perspectiva de pensar formas institucionales más abiertas que construyan la gestión de lo público a partir de agregaciones y desagregaciones desde lo local (comunitario, parroquial, municipal y otras dimensiones) hacia arriba, para reemplazar las actuales lógicas de construcción vertical de las políticas y lo público desde las autoridades y las instituciones hacia abajo. Y este aspecto también pasa por reformular los sistemas de planificación de los estados para resignificar las políticas desde los aportes de las comunidades y los territorios, y que esto se cambie con principios constitucionales para la organización y planificación de políticas sectoriales e intersectoriales. En esta perspectiva, habría que discutir según los modelos de desarrollo de cada estado si conviene o no combinar consejos específicos que pertenezcan a la institucionalidad estatal con unidades locales y territoriales de la sociedad civil para asegurar estos principios y su vinculación con los DP.

A excepción de las Constituciones de Venezuela y Ecuador, las demás no definen mecanismos específicos de participación y este es un gran debate de la democracia constitucional. ¿Es oportuno que los textos constitucionales de los países avancen hacia fijar cuáles serían los mecanismos legítimos para viabilizar los DP o la participación social?

El inconveniente de esto es que uno de sus efectos sería precisamente la restricción de las capacidades autónomas de la sociedad para participar, por cuanto eso reafirma el papel del estado para controlar y admitir únicamente las formas institucionalizadas de la participación, excluyendo a aquellas que no se proyecten por estos medios burocratizados (es decir, solo es válida la participación que el funcionario y el estado admiten y autorizan). Y algo adicional: al no estar suficientemente normadas (o regladas) para los funcionarios estatales las formas de participación no institucionalizadas, lo más común es que sean rechazadas. Ventajosamente también el texto ecuatoriano, por ejemplo, reconoce aquellas formas y mecanismos no mencionados en su estructura, pero esto tampoco garantiza que tenga la efectividad para intervenir o incidir en la agenda pública o en la institucionalidad. El otro problema que surge es cuando los actores organizados y no 
organizados desean crear o implementar un mecanismo no previsto por la Constitución y la ley, ¿este sería inviable? ¿tiene que estar siempre autorizado por la ley? ¿debe tener algún sustento constitucional o de lo contrario no podría funcionar?

Cuando observamos los textos constitucionales evidenciamos que mientras más reciente fue su aprobación (como Bolivia, Ecuador, Venezuela, Colombia y Brasil) constan más explícitos los DP y sus instrumentos de ejercicio; a diferencia con aquellos textos cuya aprobación o reforma ha sido más distante. Eso expresa el interés que ha asumido para las democracias contemporáneas ${ }^{32}$ el robustecimiento de la participación social, pero también nos lleva a pensar en el inconveniente que sería si una carta constitucional se encarga de fijar todos los instrumentos para los DP, y después de unos años, estos no lograron adaptarse en las prácticas de los movimientos y colectivos por sus distintas tradiciones e imaginarios políticos y es indispensable reformarlos; ¿qué pasaría también si la Constitución por mencionar algunos, deja por fuera a otros que pueden ser los más utilizados o los que más se ajustan a las necesidades y costumbres de la ciudadanía según sus condiciones de vida? ¿Qué pasaría con los dispositivos participativos que están por crearse, que están por surgir o que están por-venir?

Lo óptimo es que las disposiciones constitucionales reconozcan que los DP no pueden agotarse en los procedimientos representativos y que deben declarar la necesidad de que cada tipo de sociedad pueda innovar y reformular las instancias para la participación. También eso implica reconocer como un derecho y elevarlo a una categoría constitucional que el estado debe respetar y promover la acción autónoma de la sociedad para participar, y en esa orientación, establecer la prohibición de que funcionarios e instituciones públicas no podrán realizar ninguna actividad tendiente a alterar o interferir en las prerrogativas autónomas e independientes de la sociedad tanto para organizarse, como para ejercer sus DP.

Otro aspecto relevante es que los textos constitucionales deben manifestar y reconocer la capacidad de la sociedad para proponer sus propios mecanismos y la diversidad que es inherente a ella para recrearlos. Quizás podría ser pertinente discutir si conviene en diferenciar los dispositivos de participación entre aquellos propios del nivel nacional con respecto a los que pertenezcan a los niveles subnacionales. Empero, aceptando esto, ¿qué pasaría si un colectivo decide utilizar un instrumento de naturaleza local hacia el ámbito nacional? Esto nos remite nuevamente a la dependencia de la participación social frente a las autorizaciones y permisos de las autoridades estatales.

Otra pauta para la discusión estaría planteada por la posibilidad de que los cuerpos constitucionales determinen que las instituciones públicas impulsen polí-

32 Sobre este punto, cabe retomar el pensamiento de Roberto Gargarella, cuando señalaba que cuando corresponde a jueces o funcionarios públicos dar sentido a los nuevos derechos, están bien preparados para obstaculizarlos. Y afirma: "Una historia similar puede contarse en relación con la introducción de cláusulas participativas, sobre todo en la segunda oleada importante de reformas constitucionales, en el siglo XX. Para simplificar una historia larga: i) si mecanismos "promotores de la promoción cívica", como los del plebiscito y el referéndum, pueden socavar la autoridad de los Parlamentos actuales existentes, y ii) son estos, a su vez, los que quedan a cargo, constitucionalmente, de la definición o promoción de aquellos mecanismos participativos, entonces no hay muchas esperanzas que abrigar acerca de la suerte que van a correr, en lo inmediato, aquellas cláusulas": Cfr. "El nuevo constitucionalismo latinoamericano. Algunas reflexiones preliminares", en Crítica y emancipación, (3): 169-188, primer semestre 2010. 
ticas participativas y que estas puedan ser concertadas con los sujetos sociales en sus dinámicas de organización y funcionamiento porque estas no podrían estar predefinidas en el texto constitucional. Pero garantizando la pluralidad y diversidad de actores, incluyendo a aquellos que no formen parte del proceso gubernativo, directriz esta que deberá observarse en todos los niveles de gobierno.

Un tema de relevancia para profundizar los estados constitucionales radica en la necesidad de incorporar principios en la norma suprema que procuren mayores articulaciones y contribuciones entre las formas de democracia comunitaria, participativa y directa para el conjunto de los procedimientos e instituciones de la democracia representativa. Esta última requiere reconstruirse a partir de mecanismos aleatorios, cambiantes, flexibles, alternos, eventuales, contingentes y circunstanciales que abran las políticas públicas para la intervención social, y esto no es un problema de reglas, ni tampoco de que estas sean claras, ni que todos los procesos participativos consten debidamente reglamentados en los textos constitucionales, tampoco en preestablecer los dispositivos según cada nivel, sino en la enunciación de grandes obligaciones y responsabilidades a los actores institucionales y gubernativos para que implementen modelos de gestión con variados procesos de participación y fiscalización social, y que estos deberán ser cambiantes y ajustables ${ }^{33}$ según las expectativas de los propios sujetos organizados y no organizados.

Lo trascendente es que los nuevos tipos de constituciones sean capaces de construir un sistema amplio de decisiones públicas, sin agotar lo público en lo estatal, ni subsumir la democracia únicamente a la última voluntad de los mandatarios. Lo óptimo es que en ese sistema exista un cruce democrático y equilibrado de instituciones que debaten y deliberan para construir voluntades armonizadas entre procesos provenientes del estado y aquellos que se gestan en la sociedad. El camino ideal tampoco sería ahogar la representación política, empero, esta no puede en cambio ignorar ni desconocer las voluntades minoritarias y divergentes. Lo que se trata es de erigir un constitucionalismo popular que pueda articular propuestas y debates para un gran sistema decisional que no termine en la voz de las autoridades, sino en formas de procesamiento amplio y razonado que se articulen y expresen definiciones que se han gestado en distintos canales públicos (interfases socio-estatales).

\section{Consideraciones finales}

Si el gran defecto del constitucionalismo liberal fue ubicar a la representación política por encima de la participación social, una nueva vertiente no puede revertir esas posiciones, sino reconocer la importancia de un diálogo intercultural

33 Germán J. Bidart Campos manifiesta lo siguiente: "La política es continua, vital, ininterrumpida, no concluye jamás, y la gestión de poder produce día a día, en una temporalidad sucesiva, sus resultados. Nunca puede imaginarse que un buen día el fin se ha alcanzado para siempre, y que de ahí en más se produce un reparto de beneficios definitivos. No es ésa la cara dinámica del quehacer estatal, ni de la convivencia social ni de la política. La dinámica del régimen político nunca se extingue, nunca se paraliza; esa reversión de resultados es cotidiana, permanente, sin discontinuidades. De ahí que a la vez que se participa en el proceso de poder a través de la propiciada intervención con roles protagónicos activos, se opera simultáneamente el resultado del mismo proceso de poder, en una especie de ciclo de retroalimentación sin pausa": Cfr. Constitución y derechos humanos. Su reciprocidad simétrica (Buenos Aires: Ediar, 1991), 210. 
para ambas; y así, se resolverían las siguientes discusiones: ¿Hasta qué espacios institucionales la participación social es vinculante?, o ¿cómo afrontar las contrariedades de la falta de efectividad de la participación para la toma de decisiones?, y, finalmente ¿cómo generar más obligatoriedad para la participación hacia el estado y hacia la sociedad?

Los estados latinoamericanos deben innovar hacia constitucionalismos renovados que puedan equilibrar los procesos decisionales para los distintos tipos de democracia. Un problema actual muy recurrente es que la mayoría de decisiones son tomadas por los mandatarios y las vertientes institucionales representativas, pero ahí la pregunta es ¿qué agendas, políticas y procesos dejamos para que decidan las formas comunitarias, directas y participativas?

No se trata de crear esquemas institucionales paralelos, ni tampoco deslegitimar a los actores partidarios y su intervención decisional. Sino de asegurar instancias deliberativas, modelos de gestión y de gobierno que se reproduzcan en esas instancias, y para ello, el presidencialismo sí constituye un gran obstáculo para esas transformaciones.

Un constitucionalismo emancipador requiere no definir con precisión los dispositivos y sus reglas, sino renovar el estado, el Derecho y sus tradiciones institucionales para asegurar procesos dialogantes que permitan que el poder circule y se democratice entre procesos y organizaciones, y no solamente que se concentre en ciertas personas. Eso permitiría que las sociedades aseguren sus libertades públicas para crear colectivos, tendencias, coaliciones, frentes sectoriales, organizaciones temáticas que generen condiciones políticas espontáneas de participación y que puedan ser moldeables según cada realidad, no camisas de fuerza ni libretos tutelados de simulacros para los derechos políticos.

Cuando es impostergable la reinvención de los estados, estoy hablando de crear condiciones auténticas de información y transparencia sobre las políticas. También implica que las dependencias públicas funcionen para dar respuestas, para atender el conjunto de los derechos de los individuos. Se trata de que las normas constitucionales aseguren procesos y procedimientos de gestión con diseños que desconcentren el poder y la toma de decisiones, con responsabilidades para procesar adecuadamente las expectativas sociales.

El desafío es volver a conectar las instituciones con el quehacer social, no hacer que la sociedad reemplace a los organismos estatales. El constitucionalismo social moderno que se anhela no es poner a los sujetos sociales contra el estado, ni a mandatarios que persigan a los líderes y activistas. Los retos deben caminar hacia construir interrelaciones más virtuosas, eficientes y con resultados para que el sentir y la voz de las personas se convierta en fuente de Derecho y de derechos.

Una orientación clave para el desarrollo de un control social democrático consistiría en que los textos constitucionales asuman la fiscalización popular de las políticas públicas para que contribuyan a aportar en sus falencias y a mejorar el ciclo de implementación. El quehacer de los sujetos sociales debe estar pensado para contribuir a esclarecer en qué fallan las políticas, identificar las deficiencias en su diseño, ejecución, e inversión y hacer el seguimiento con miras a perfeccionar 
las políticas. Esa sería otra directriz importante de los cambios constitucionales: no existirá implementación de políticas públicas sin fiscalización social, y sobre este punto la garantía en esta materia presente en el texto ecuatoriano es un logro valioso. Empero, una garantía de política sin la institucionalidad que la proteja no es viable, porque ese acumulado político de incidencia de los movimientos sociales para direccionar las políticas debe ser preservado no sólo por un interés estatal de encontrar ahí un mecanismo de corrección, sino por el potencial participativo que eso desembocaría.

Los diseños constitucionales necesitan fortalecerse para articular mejor los procesos participativos con los ciclos de las políticas públicas, y todo eso atravesado por múltiples formas de accountability horizontal impulsadas desde los sujetos sociales, más que desde agencias estatales. Estos énfasis permitirían un control social desde abajo hacia la acción de las autoridades para influir e incidir en sus contenidos y visiones.

Los modelos institucionales que puedan ser modificados desde las normas constitucionales deben contener las alertas necesarias para insertar fórmulas programáticas y operativas que aseguren pluralidad y equidad en los procedimientos representativos y participativos tanto de la ciudadanía como del estado, y cuando hablamos de la ciudadanía debemos pensar en los sujetos organizados y no organizados; y cuando hablamos del estado debemos advertir que este cuenta con tendencias autoritarias y concentradoras muy fáciles de encenderse y que merecen los contrapesos sociales ineludibles.

Otra advertencia acertada es que la creación de diferentes órganos como consejos de estado u de otro tipo para promover los derechos políticos no es una garantía de que vayan a funcionar en esa dirección. Y lo más factible es que puedan convertirse en espacios de cooptación, fragmentación o división de las organizaciones sociales y volvemos a reeditar el fenómeno de la estatización e institucionalización de la participación. Los sentidos constitucionales para nuevas políticas democráticas deben vislumbrar que lo idóneo es preservar y cuidar que la movilización y organización social funcione, para lo cual es pertinente crear protecciones y garantías en distintos niveles y bajo principios claros de responsabilidad para los funcionarios públicos. Lo interesante es también que la ciudadanía tenga las condiciones para hacer seguimiento y evaluar al estado y sus políticas en la medida en que vea reflejados sus intereses en estas últimas, para que en caso de que esto no ocurra cuente con los medios procedimentales para exigir sus derechos.

Otro aviso a tiempo para que el constitucionalismo latinoamericano adopte los reparos necesarios es que los órganos de control constitucional y de administración de justicia deben contar con niveles más amplios de representación y participación social, y cuando digo esto me refiero a plantear como principios constitucionales que esos organismos deben adoptar procedimientos que no restrinjan ni limiten los DP. El debate reside en cómo vamos sugiriendo también obligaciones para articular ámbitos y niveles de funcionamiento de estas instancias con otros saberes e intervenciones sociales. Los eslabones entre las posibilidades para que la sociedad participe e incida en la justicia constitucional deben adoptarse también 
en las políticas públicas que la organizan y también en la fijación de políticas que aseguren su independencia frente a las fuerzas políticas gobernantes.

Otra pauta a cuidar es que los textos constitucionales no pueden definir esquemas de participación y ejercicio de derechos políticos pensando en un solo modelo de actor social y político, porque somos sociedades con una multiplicidad de actores que no puedan cerrarse en esquemas unidireccionales para usar sus derechos. Una tensión que la generan ciertas cartas constitucionales es poner unas reglas de juego para la participación política que están pensadas para los sujetos sociales que se adhieren y apoyan las políticas de un gobierno en funciones. Por ello, las innovaciones constitucionales deben pensar en crear reglas para aquellos actores que no se identifiquen ni se sientan parte de los procesos gubernativos, pero que sí les interesa intervenir en las políticas para mejorarlas y encontrar sus mejores alternativas.

Existen movimientos y colectivos que tienen sus propias propuestas de políticas que no pueden ser invisibilizados ni excluidos, y peor aún desde el mismo sistema constitucional. Otro desafío es construir proyectos que constitucionalicen la democracia reconociendo la vida y libertades de los individuos y pueblos para ser parte de las políticas respetando sus particularidades e identidades propias.

Nuestros países deben implementar políticas públicas orientadas a promover el uso de los DP mediante la entrega de fondos no reembolsables para proyectos que coadyuven en su ejercicio con la finalidad de no depender de la disponibilidad de recursos económicos por parte de los sujetos sociales y políticos.

La ampliación e intensificación de los derechos de participación hacía ámbitos poco utilizados como las políticas económicas en materia de finanzas públicas permitirá contribuir al desarrollo de un derecho de responsabilidad, calidad y fiscalización social al gasto público de los estados.

Los estados deben utilizar las constituciones para reforzar los ámbitos de las políticas y las intervenciones de los sujetos sociales sin perjuicio del tipo de actor social y sus posiciones de coincidencias o divergencias con respecto a los gobiernos, promoviendo y definiendo condiciones materiales para sus DP en los ámbitos y relaciones interinstitucionales de esas políticas.

\section{Bibliografía}

Aguilar de Luque, Luis (2004). Los derechos políticos. En Pablo Pérez Tremps (coord), Los derechos fundamentales. Serie 3, Quito: Corporación Editora Nacional / Tribunal Constitucional / Universidad Carlos III / Iniciativa Europea para la Democracia y los Derechos Humanos de la Comisión Europea.

Bidart Campos, Germán J. (1991). Constitución y derechos humanos. Su reciprocidad simétrica. Buenos Aires: Ediar.

Bresser Pereira, Luiz Carlos y Nuria Cunill Grau (1998). Entre el Estado y el mercado: lo público no estatal. En Luiz Carlos Bresser-Pereira y Nuria Cunill 
Grau, editores, Lo público no-estatal en la reforma del Estado, Caracas: CLAD / Buenos Aires: Paidós.

Brigham, John (1987). Las libertades civiles y la democracia estadounidense. México: Gernika.

De Sousa Santos, Boaventura y Leonardo Avritzer (2004). Introducción: para ampliar el canon democrático. En Boaventura de Sousa Santos, coordinador, Democratizar la democracia. Los caminos de la democracia participativa. Colección Sociología, México D.F., Fondo de Cultura Económica.

Font, Joan (2001). Introducción. En Joan Font (coord.), Ciudadanos y decisiones públicas. Barcelona: Ariel.

Gargarella, Roberto (2010). El nuevo constitucionalismo latinoamericano. Algunas reflexiones preliminares. En Crítica y emancipación (3), 169-188, primer semestre.

Leiras, Marcelo (2007). La incidencia de las organizaciones de la sociedad civil en las políticas públicas. Definiciones, explicaciones y evaluaciones de la literatura especializada local e internacional. En Carlos H. Acuña y Ariana Vacchieri (comp.), La incidencia política de la sociedad civil. Buenos Aires: Siglo XXI.

Newman, Frank C. y Vasak Karel (1984). Derechos civiles y políticos. En Karel Vasak (ed.), Las dimensiones internacionales de los derechos humanos. París: Unesco.

Pérez Luño, Antonio Enrique (1999). Derechos humanos, estado de derecho y constitución, Madrid: Tecnos.

\section{Normativa}

Constitución de la República del Ecuador [2008], tít. II, "Derechos", cap. V, arts. 61, 96, 98, Registro Oficial No. 449, de 20 de octubre de 2008.

Pacto Internacional de Derechos Civiles y Políticos [1966], adoptado y abierto a la firma, ratificación y adhesión por la Asamblea General en su Resolución 2200 A (XXI), de 16 de diciembre de 1966 y con entrada en rigor el día 23 de marzo de 1976 de conformidad con el artículo 49, disponible en portal web institucional de la Agencia de la ONU para Refugiados, en la dirección <http://www.acnur.org/t3/fileadmin/scripts/doc.php?file=biblioteca / pdf/0015>. Consulta: 26 de diciembre de 2014.

Convención Americana sobre Derechos Humanos [1969] suscrita en la Conferencia Especializada Interamericana sobre Derechos Humanos (B-32) disponible en portal web de la Organización de los Estados Americanos en la dirección <http://www.oas.org/dil/esp/tratados_B32_Convencion_Americana_sobre_Derechos_Humanos.htm>. Consulta: 26 de diciembre de 2014.

Constitución Política del Perú [1993], tít. I, "De los Derechos Políticos y de los Deberes", cap. III, arts. desde 30 hasta 38, disponible en portal web institucional del Congreso de la República de Perú, en la dirección <http:/ / 
www4.congreso.gob.pe/ntley/Imagenes/Constitu/Cons1993.pdf >. Consulta: 22 de diciembre de 2014. También consulté la versión publicada en el portal web institucional del Tribunal Constitucional de Perú, en la dirección <http://www.tc.gob.pe/constitucion.pdf > , actualizada hasta la modificación incorporada por la Ley No. 28480 publicada el 30-03-2005 en el Diario Oficial El Peruano. Consulta: 25 de diciembre de 2014.

Constitución de la Nación Argentina [1994], primera parte, "Nuevos derechos y garantías", cap. II, arts. desde 36 hasta 40, disponible en portal web institucional del Senado de la Nación Argentina, en la dirección <http://www.senado. gov.ar/Constitucion/capitulo2>. Consulta: 22 de diciembre de 2014. También revisé la versión publicada por la Biblioteca del Congreso de la Nación, actualizada hasta la promulgación de la Ley 24.430, publicada en Boletín Oficial de la República Argentina el día 10 de enero de 1995 y disponible en el portal web institucional con la dirección <http://bibliotecadigital.csjn. gov.ar/Constitucion-de-la-Nacion-Argentina-Publicacion-del-Bicent.pdf $>$. Consulta: 25 de diciembre de 2014.

Constitución Politica de la República de Colombia [1991], tit. II, "De los Derechos, las Garantías y los Deberes", cap. I, arts. 40 y 41, disponible en el portal web de la Imprenta del Gobierno en <http://www.imprenta.gov.co/portal/page/ portal/IMPRENTA/la_imprenta/Normatividad $>$ que contiene la última modificación por el Acto Legislativo 1 de 2008, publicada en el Diario Oficial No. 47.214 de 2008. Consulta: 22 de diciembre de 2014.

Constitución de la República Federativa de Brasil [1988], tít. I, "Nuevos derechos y garantías", cap. IV y V, arts. desde 14 hasta 17, traducción hecha por Antonio López Díaz y César García Novoa del texto vigente de 1988, promulgada el día 5 de octubre de 1988 y publicada en el Diario Oficial da Uniao No. 191-A del día 5 de octubre de 1988. La versión consultada está publicada en Brasilia: Centro Gráfico del Senado Federal, 1990, disponible en portal web de la biblioteca jurídica de la Universidad Nacional Autónoma de México, en la dirección <http://biblio.juridicas.unam.mx/libros/4/1875/2.pdf>. Consulta: 22 de diciembre de 2014.

Constitución de la República Bolivariana de Venezuela [1999], tít. I, "Nuevos derechos y garantías", cap. IV y V, arts. desde 14 hasta 17, publicada en la Gaceta Oficial Extraordinaria No. 36.860 de fecha 30 de diciembre de 1999, disponible en portal web de la Organización de Estados Americanos, en la dirección <http://www.oas.org/dil/esp/Constitucion_Venezuela.pdf >. Consulta: 22 de diciembre de 2014.

Constitución del Estado Plurinacional de Bolivia [2009], tít. II, sección II, "Derechos Políticos", cap. III, arts. desde 26 hasta 29, publicado con fecha 7 de febrero de 2009, en la Gaceta Oficial del Estado Plurinacional de Bolivia, disponible en portal web de la Vicepresidencia Plurinacional de Bolivia en el sistema de información legal del Estado Plurinacional, en la dirección http:// www.silep.gob.bo/silep/constitucion. Consulta: 22 de diciembre de 2014.

Constitución Politica de la República de Chile [actualizada hasta 2014], tít. II, sección 
II, "Nacionalidad y ciudadanía”, cap. II, arts. desde 15 hasta 18, publicada con última reforma mediante Ley 20748 D.O. 03.05.2014 en el Diario Oficial de Chile, disponible en portal web de la Biblioteca del Congreso Nacional de Chile en la dirección <http://www.leychile.cl/Navegar?idNor$\mathrm{ma}=242302>$. Consulta: 23 de diciembre de 2014 .

Constitución de la República Oriental de Uruguay [1997 con la última enmienda en 2004], sección III, "De la ciudadanía y del sufragio", cap. II, arts. desde 77 hasta 78. La versión utilizada tiene derechos reservados por su autor y por Industria Gráfica Nuevo Siglo Ltda./Editorial Jurídica de Uruguay Eduardo Esteva/Ingranusi Ltda. El texto de la Constitución que entró en vigor en 1967 es reproducción del incluido en el Registro Nacional de Leyes y Decretos, 1967, t.I, ps. 119-203. El de la reforma constitucional parcial plebiscitada el 8-XII-1996 fue tomado del Diario Oficial No. 24.701, de 9-I-1997. Los de las enmiendas parciales plebiscitadas el 26-XI-1989 y el 27-XI-1994 reproducen los textos de los respectivos proyectos de reforma constitucional, no publicados en el Diario Oficial. Esta versión está disponible en portal web de la Biblioteca de la Universidad Nacional Autónoma de México en la dirección <biblio.juridicas.unam.mx/libros/4/1739/15. pdf>. Consulta: 23 de diciembre de 2014.

Constitución Politica de los Estados Unidos Mexicanos [1917 actualizada hasta reforma de 2014], "De los ciudadanos mexicanos", cap. IV, art. 35, expedida con última reforma de fecha 25 de junio de 2014 y publicada en la primera sección del Diario Oficial de la Federación con fecha 7 de julio de 2014, disponible en portal web del H. Congreso de la Unión, Legislatura LXII, en la dirección<http://www.diputados.gob.mx/LeyesBiblio/ref/cpeum_crono.htm>. Consulta: 23 de diciembre de 2014. También consulté la versión del texto publicada por la Secretaría de la Gobernación, actualizada hasta septiembre de 2014, vigésima primera edición al cuidado de la Dirección General Adjunta del Diario Oficial de la Federación, México, D.F., Talleres Gráficos de México, 2014, disponible en la dirección <http://www.dof. gob.mx/constitucion/marzo_2014_constitucion.pdf $>$. Consulta: 25 de diciembre de 2014. 